\title{
Growing Season Climate Variability and its Influence on Sauvignon Blanc and Pinot Gris Berries and Wine Quality: Study Case in Romania (2005-2015)
}

\author{
E. Nistor ${ }^{1 *}$, A.G. Dobrei ${ }^{1}$, A. Dobrei ${ }^{1}$, D. Camen $^{1}$ \\ (1) Banat University of Agricultural Sciences and Veterinary Medicine "King Michael I of Romania" from Timisoara, Calea \\ Aradului 119
}

Submitted for publication: November 2017

Accepted for publication: September 2018

Key words: climate, grapes, Pinot Gris, rainfall, Sauvignon Blanc, sugar, temperature, wine, Romania

\begin{abstract}
The purpose of our research was to find out what influence climatic variability in the growing season has on the berry and wine composition in two white grape varieties grown in the vineyard of Banat University of Agricultural Sciences and Veterinary Medicine from Timisoara, located in the western area of Romania. The quality and characteristics of the wines produced in a limited area is essentially due to the environment, including natural and human factors. Two white cool-intermediate climate grape varieties - Sauvignon Blanc and Pinot Gris were chosen to study the impact of climate change on the main characteristics of juice and wine. A number of $\mathbf{4 0}$ berries from each variety was chosen for phenol extraction, total soluble solids (sugar content), titratable acidity and pH determinations. Wine samples were analysed after one year of ageing in the bottle. Alcohol concentration was not majorly influenced by temperature and rainfall over the years. Some experimental years with hot weather were favourable for sugar accumulation in berries and wine respectively; therefore, potential alcohol also increased. In the last decade, annual and monthly variability of rainfall and temperature influenced the phenological cycle of grapevines most, delaying or accelerating the developing of foliar area, as well as the ripening and harvesting time, which has a direct influence on grapes and wine products.
\end{abstract}

\section{INTRODUCTION}

Recent climate variability including major temperature differences from summer to winter, alternating hot, dry days and cold, rainy days negatively influenced the grape yield and quality. This is not only the case in Romania, but all over the world (Nesbitt et al., 2016). The World Meteorological Organization (WMO) reported that Europe experienced its second hottest year in 2015, behind only the record set in 2014. The rising temperatures associated with climate change are already reshaping the wine industry; therefore, viticulturalists match the varietal with the environmental factors of a region (Jones et al., 2012). There is a clear correlation between grapevines and climate change. As a result of phenological stage changes, harvest time has shifted from late October to early September over the last 25 years in many vineyards located in France, Italy and Germany (McQuaid, 2011\& Daux et al., 2011). Climate variability in Romania generates beneficial and adverse consequences. The area of vineyards was expanded in terms of climate suitability for better wine production by 2.4 million hectares. Red wine grape varieties were introduced in northern regions, while grape composition was influenced by excessive sugar levels and lower acidity in southern regions (Irimia et al., 2017). Despite climate variability that has occurred throughout history, vine cultivation and wine making have survived through continuous adjustment (Ashenfelter \& Storchmann, 2014).However, these adjustments seem to be slower for vines that have a productive lifetime of over 25 years than for annual crops (Cooper et al., 2012). Grape yield and wine quality, and therefore prices and revenues, are directly influenced by weather, both during the season and at harvest (Lorenzo et al., 2012). Temperature, humidity and solar radiation have great influence on grapevine growth, fruit set, grape yield and wine quality, as Bora et al. (2016) reported in their research concerning the wine quality from several Romanian and worldwide vintages, including Sauvignon Blanc, Italian Riesling and Muscat Ottonel. Yield and grape quality from the same plot can vary from year to year depending on climate (Ashenfelter et al., 1995). Berry composition is influenced by climate, viticultural practices and topography (Jackson, 2000). During ripening, phenols and especially tannins are developed in the skins and seeds of the grape, and can affect the wine flavours and 
aromas (Weston, 2000). Temperature has a deep impact throughout grape growing season. After veraison starts, sugars build up (fructose and glucose accumulate) and $\mathrm{pH}$ (acids) begins to fall (Robinson \& Harding, 2015). The heat hastens ripening, producing grapes with more sugar, stronger flavors, and wine with more alcohol.However, over $33^{\circ} \mathrm{C}$ photosynthesis and, in consequence, berry ripening is slowing down (Jones \& Davis, 2000). Some researchers state that high day temperatures combined with low temperatures overnight stimulates phenolic compounds with positive results for wine quality (Jones \& Alves, 2012). In relatively closed locations, the same grape wine variety can offer special traits with its own typicity and strong footprint (Dobrei et al., 2015).

Research was carried out with the aim to assess the influence of climate variability, temperature and precipitation on grape berries and wine quality in Sauvignon Blanc and Pinot Gris varieties grown in the vineyard of Banat University of Agricultural Sciences and Veterinary Medicine from Timisoara, during 2005-2015. Research is important for winemakers to be able to evaluate the opportunities and risks, including those from the well-known vineyards Recas, Minis and Buzias-Silagiu in western Romania in order to adapt the growing practices according to the region climate to preserve the typicity of white wines in the region, knowing the harsh competition in the wine industry.

\section{MATERIALS AND METHODS}

The trial was conducted at the Banat University of Agricultural Sciences and Veterinary Medicine from

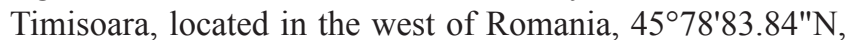
$21^{\circ} 22^{\prime} 60.11^{\prime \prime E}$, latitude and longitude coordinates (Fig. 1), during 2005-2015.
Climate in the region is moderate continental with slight Mediterranean influences. The average annual temperature is $10.9^{\circ} \mathrm{C}(1961-2015)$, with a maximum of $41^{\circ} \mathrm{C}$ registered on $16-08-1952$ and a minimum of $-35.3^{\circ} \mathrm{C}$ on $29-01-1963$. Two white cool-intermediate climate varieties - Sauvignon Blanc and Pinot Gris - grown in the same vineyard of 22 years old were used in the study. The vines were planted on rows oriented west to east, at $1.2 \mathrm{~m}$ between vines and $2 \mathrm{~m}$ mid-row (4166 vines/ha). Vines training on trellis were Cordon de Cazenave and pruned at 30 buds per vine (two buds/spur). The vineyard is located on a flat field on a fertile cambic chernozem (silty clay, fine loess deposits) in the upper $50 \mathrm{~cm}$. Temperature was measured by sensors installed at $1.5 \mathrm{~m}$ above the ground, year-round at each third hour to create daily maximum measurements by using a WMS25 Modular Weather Station with standard SD card with 2 GB for data storage, placed in the vineyard at $35 \mathrm{~m}$ away from paved surfaces to avoid the retained heat. WMS- 25 is equipped with 6 standard weather parameters: wind speed and direction, temperature, relative humidity, barometric pressure and precipitation. Data from the SD card were transferred to a computer in Microsoft Excel for graph and data analysis.

Using our own protocol, clusters for the experiment were selected on shoots of similar vigour on vines. Each year, berry samples were collected at harvest from different places within the cluster, placed in plastic bags and stored in cooler box. Samples were taken to the laboratory and was separated in sub-samples, put in sealed plastic bags and stored at $-18^{\circ} \mathrm{C}$ until analysed. A number of 40 berries from each variety for phenol extraction and other components analyses was chosen. Berries were manually crushed for juice extraction. For total phenolic determination 10 berries were used; the

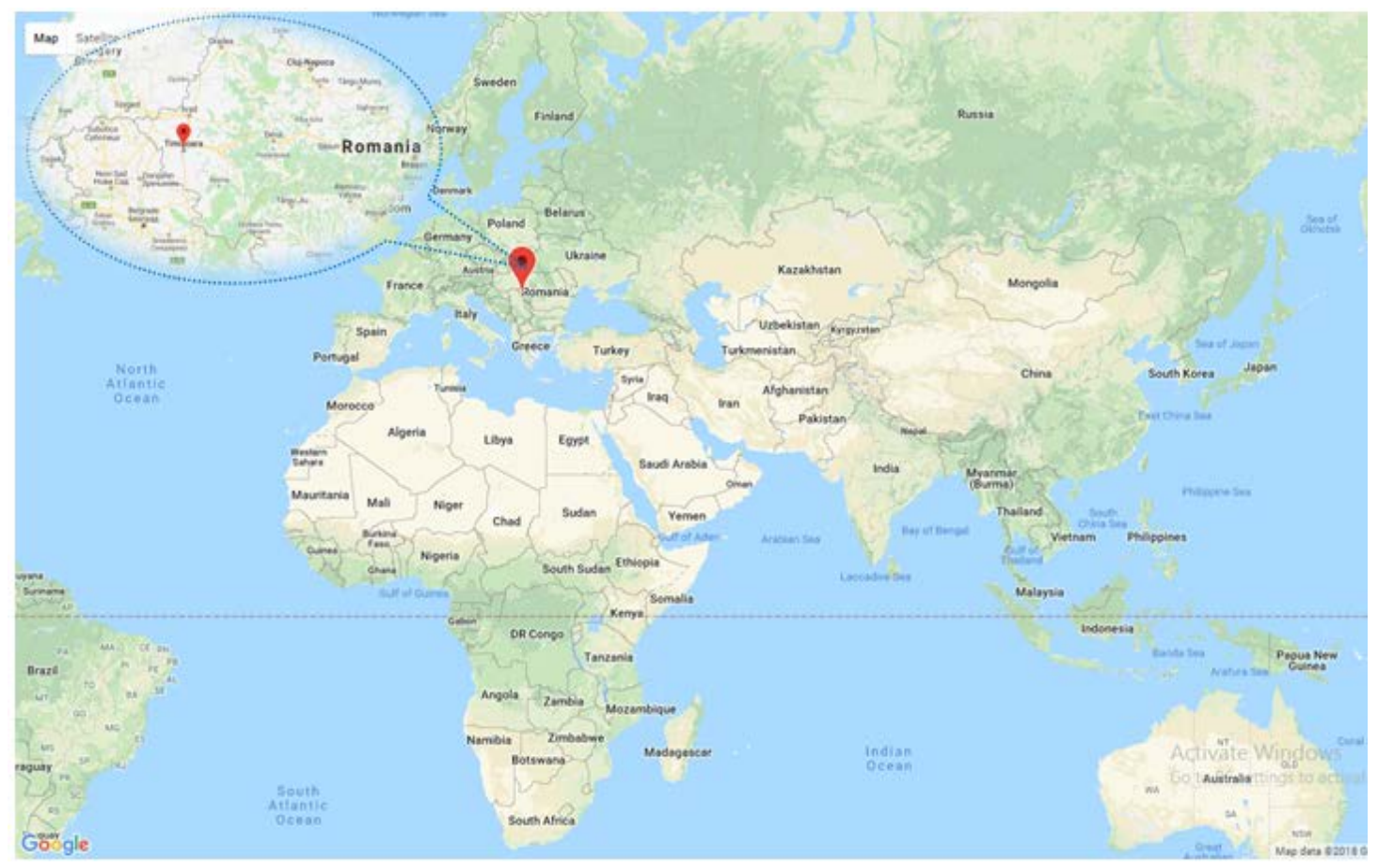

FIGURE 1

Research location (Timisoara) in western Romania (457 $\left.78^{\prime} 83.84^{\prime \prime} \mathrm{N}, 2^{\circ} 22^{\prime} 60.11^{\prime \prime} \mathrm{E}\right)$

(http://street-map.us/gps/) 
remaining berries were reserved for determining total soluble solids (sugar content), titratable acidity and $\mathrm{pH}$. Soluble solids were determined using a handheld refractometer, $\mathrm{pH}$ and titratable acidity (TA) was determined with a $\mathrm{pH}$ meter. TA was determined by titration with $0.1 \mathrm{NaOH}$ $((\mathrm{TA}=($ no.ml NaOH/ no.ml juice $) \times 0.75))$ and results are expressed as tartaric acid equivalents per litre of juice $(\mathrm{g} / \mathrm{L})$. Determination of the total phenol content was done by using the Folin-Ciocalteu method adapted from Singleton and Rossi (1965), and expressed as gallic acid equivalent (GAE) (mg/100g dry weight basis). All wines were produced under the same conditions in the BUAS winery. The wine samples from 2005 until 2015 vintages were analysed after one year of ageing in the bottle. Wine bottles were stored at $10^{\circ} \mathrm{C}$ prior to analysis. Ien the statistical analysis,data were subjected to Microsoft Excel 2013 and Statistica 7.1 (Dell Statistica, Tulsa, Oklahoma, USA) at a 0.05 level of significance. In all experiments, data were subjected to a coefficient of determination and graphical representations using Excel 2013 (Microsoft Corporation, Redmond, Washington, USA). The average monthly temperature and monthly total precipitations were calculated for the period 2005-2015 (Fig. 2 and 3) and registered data in the research region for 1961-2015 (Fig. 4). Resulted values for grapes and wines were subjected to ANOVA for both varieties. Five traits (alcohol, sugars, titratable acidity, and $\mathrm{pH}$ (for grape juice and wine)) were tested for the influence of two main weather effects (temperature and precipitations). A separate analysis was performed for each variety, and tables and graphs were produced. Predictions for sugar content in Sauvignon Blanc and Pinot Gris, depending on average monthly rainfall (2005 - 2015), were subjected to a polynomial regression model calculated with Microsoft Excel 2013, and corresponding
$\mathrm{R}^{2}$ values resulted. For veraison months (June and August), predictions of sugar content influenced by average monthly temperature (2005-2015) were made. A principal component analysis (PCA) was developed for analysing Sauvignon Blanc and Pinot Gris varieties' main parameters from grape juice and wine, related to the temperature and rainfall variability during 2005-2015 (XLSTAT, 2014).

\section{RESULTS}

\section{Climatic conditions}

Thermal and rainfall variability over growing season (Fig. 2 and 3 ) influenced the vegetation start and phenology of grape vines with significant differences in crop yield and quality, including influences on premium quality wine (Malheiro et al., 2013). Between 2005 and 2015, in March, the average monthly temperatures were within normal limits for budburst time, except in 2005 and 2006 when there was colder weather. In March in the Timisoara region, when bud break stage is starting at over $10^{\circ} \mathrm{C}$, the mean temperature was highly variable, from $1.36^{\circ} \mathrm{C}$ to $12^{\circ} \mathrm{C}$. There were days in both 2005 and 2006 when variability ranged from a minimum of $-15^{\circ} \mathrm{C}$ to $20^{\circ} \mathrm{C}$; buds were vulnerable due to high temperature amplitude and young shoots were damaged by spring frost. Flowering began about 52 days after bud break in 2012, for the shortest period (a warm and wet year), and about 73 days after bud break in the longest interval, which was in 2005 (cold with low rainfall from May to August).

In 2008, 2010 and 2013, flowering time and fruit set were both negatively influenced by rain, because many flowers were not fertilised, and crop yield declined. Limited water stress and canopy management from years 2008, 2009, 2012 and 2015 lead to early veraison and high quality wine. During ripening time (September-October), the highest
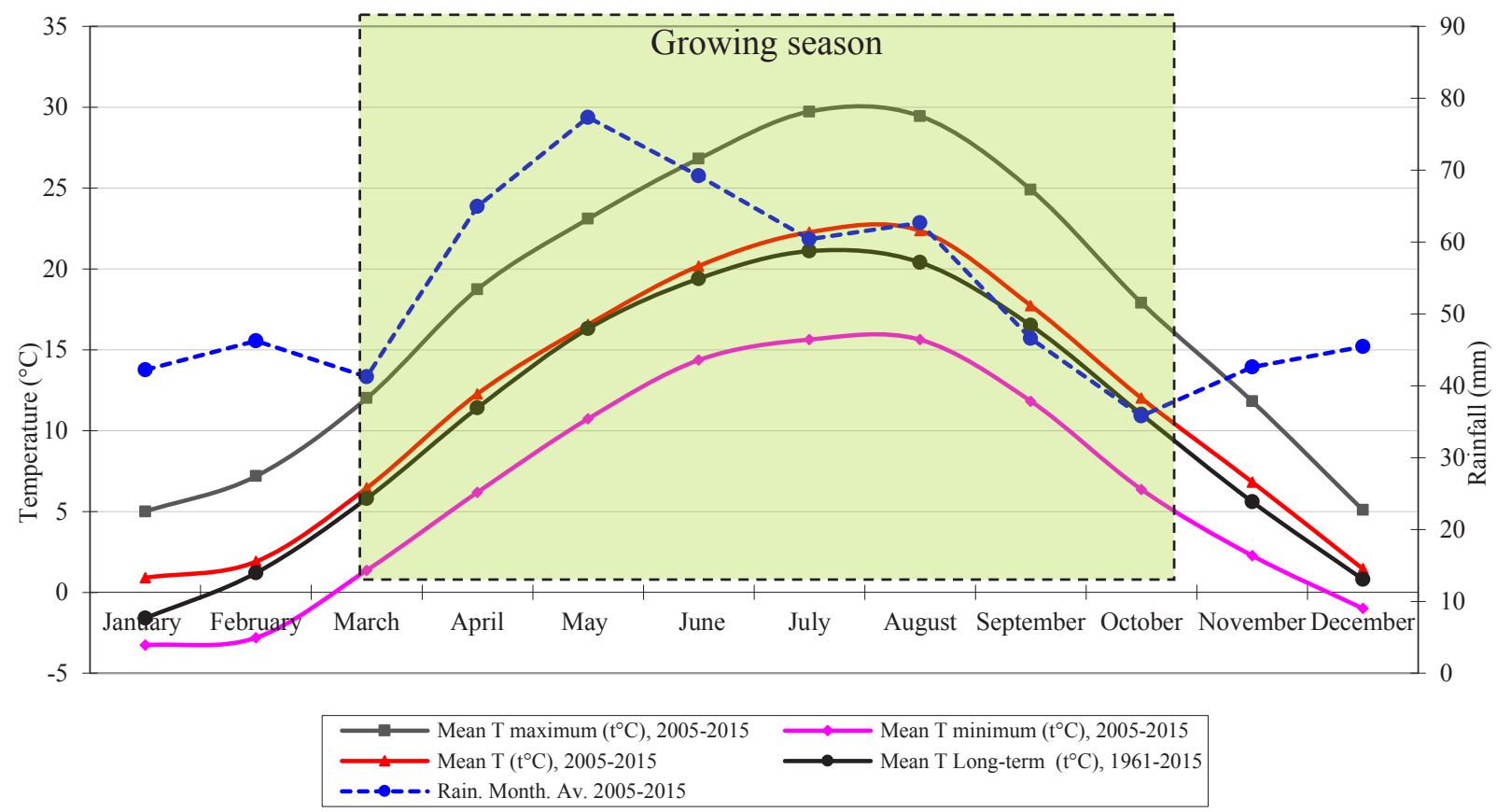

FIGURE 2

Temperature and rainfall monthly average during 2005-2015, and long term average temperature (1961-2015) in Timisoara region, Romania 
monthly average temperature was recorded in $2011\left(22^{\circ} \mathrm{C}\right)$ and the lowest monthly average temperature in $2010\left(9.5^{\circ} \mathrm{C}\right)$. High temperatures in winter months influenced the grapevine phenology, disturbed its development and shortened its vegetation. In all the years of research, the average monthly temperature in December was above $1{ }^{\circ} \mathrm{C}$, which is quite warm for a winter month, except in 2009, 2012 and 2014 when the average monthly temperature was below $0^{\circ} \mathrm{C}$. Similar observations were made for February.

During the growing season (April - September), in May, June and July were registered the most variable total average rainfall, especially during the last five years of research (2010-
2015). During 2005-2015 growing seasons, 2014/2015 could be classified as the driest (372 mm rainfall) and 2013/2014 as the wettest ( $738.4 \mathrm{~mm}$ rainfall). In the long term, rainier periods during growing season were observed in the years 1974-1975 (Fig. 4). The influence of this climate variability over 11 years (2005-2015) was studied for Sauvignon Blanc and Pinot Gris varieties in the west of Romania.

\section{Sauvignon Blanc and Pinot Gris juice and wine traits during 2005-2015}

Sauvignon Blanc originates from the regions of Loire Valley and Bordeaux in France. This variety performs well in a cool

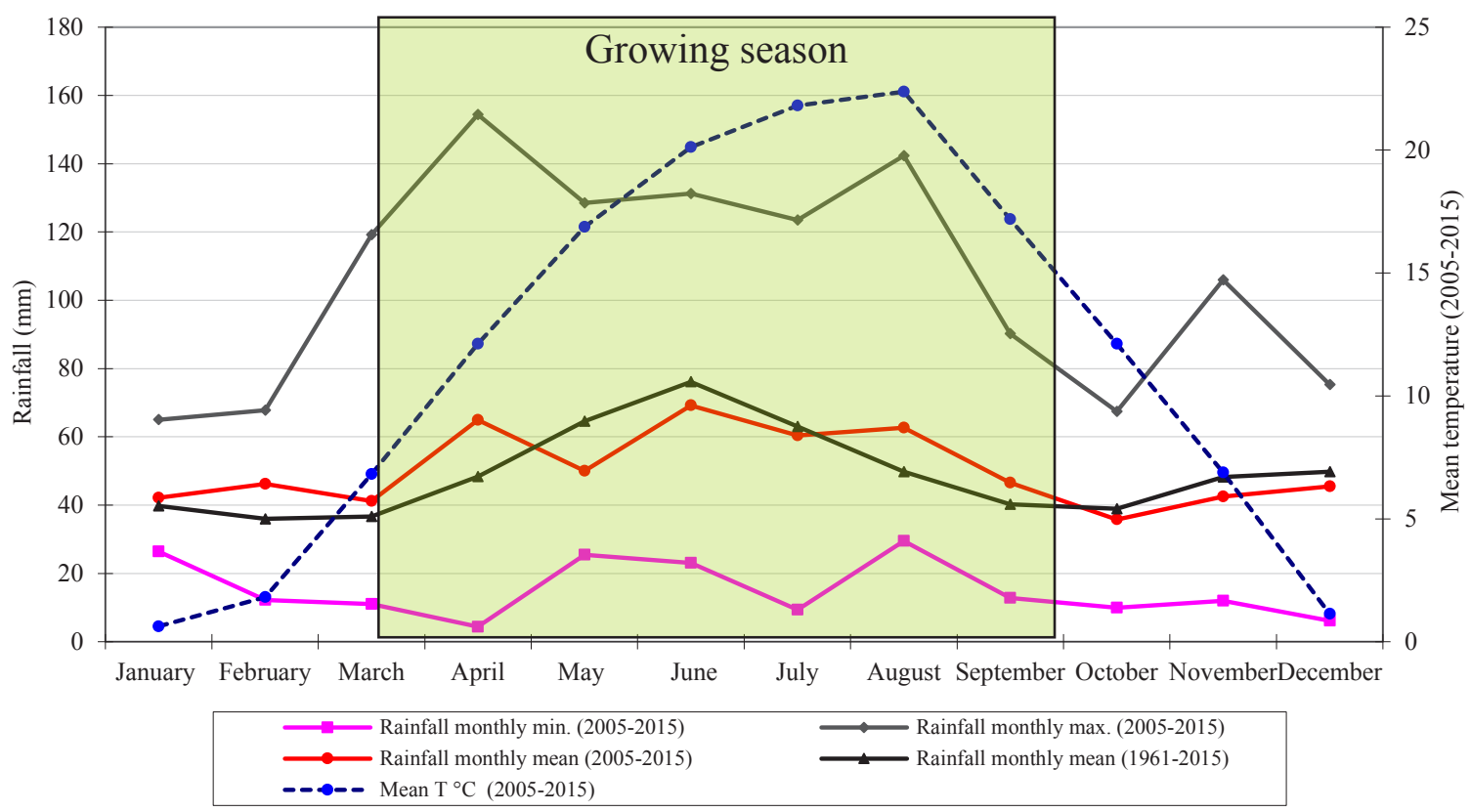

FIGURE 3

Rainfall and mean temperature during 2005-2015, and long term average monthly rainfall (1961-2015) in Timisoara region, Romania

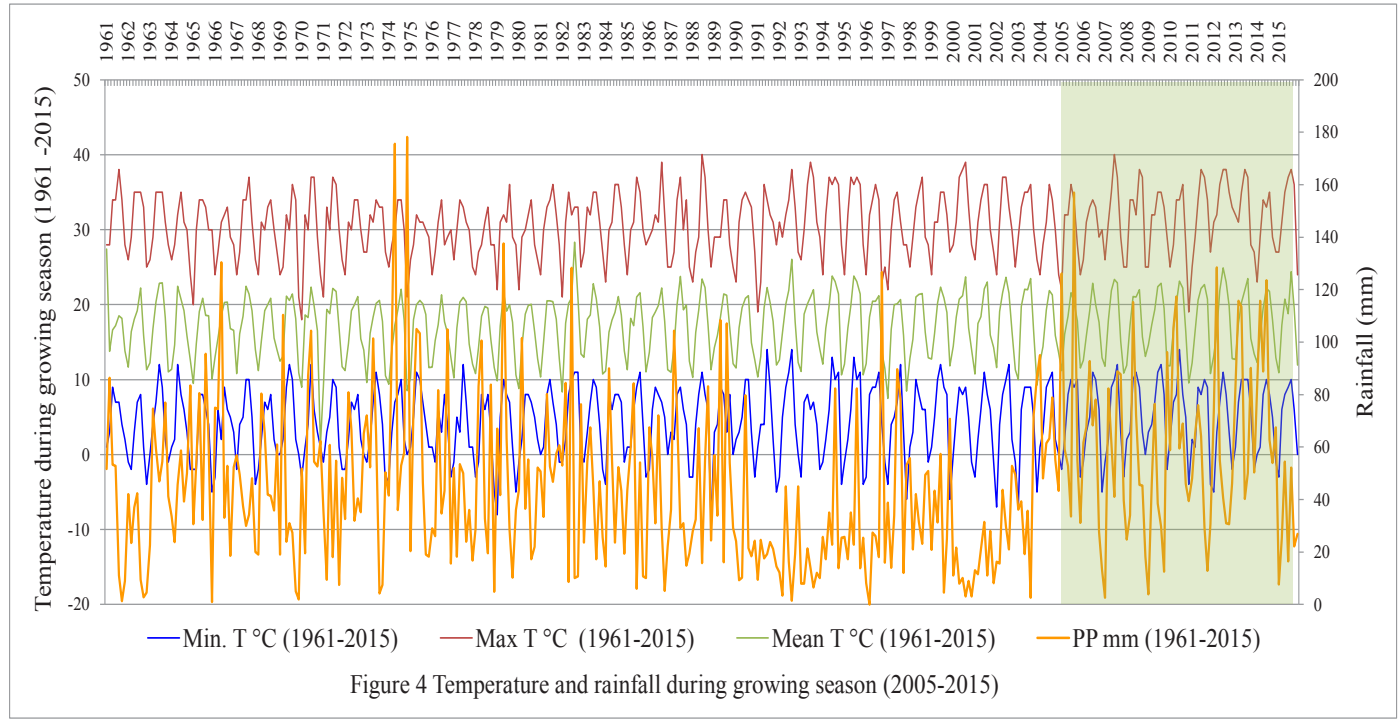

FIGURE 4

Temperature and rainfall during growing season (2005 - 2015) 
climate (Clarke et al., 2001), and depending on the climate it can offer a large range of wine styles (Coetzee \& du Toit, 2015). Pinot Gris is well known from the Middle Ages in the Burgundy region, from where it spread to many countries of the world (Robinson, 1986). According to Jones et al. (2009), varieties suited for cool climates perform well at $13-15^{\circ} \mathrm{C}$ (Pinot Gris) and $15-17^{\circ} \mathrm{C}$ (Sauvignon Blanc) in the growing season, with cooler summer days and a short period of veraison.

\section{Sugar accumulation and alcohol level}

During our research (2005-2015), grape juice sugar levels in Sauvignon Blanc oscillate from lower, $204 \mathrm{~g} \mathrm{~L}^{-1}$ in 2005, to the highest, $249 \mathrm{~g} \mathrm{~L}^{-1}$ in 2015 (Table 1). In Pinot Gris, the highest sugar content in grape juice was recorded in
2015 (260 $\left.\mathrm{g} \mathrm{L}^{-1}\right)$, followed by 2012 (254 $\left.\mathrm{g} \mathrm{L}^{-1}\right)$, with the lowest value of $219 \mathrm{~g} \mathrm{~L}^{-1}$ observed in 2005 (Table 2). The year 2015 ranked amongst the 10 warmest years on record, especially in South East Europe (Christidis et al., 2015), and was favourable for sugar accumulation compared to other experimental years. Drought associated with low temperature during ripening had a positive effect on sugar concentration in berries (Gerós et al., 2012). Therefore, alcohol levels in wine also increased. Fruit composition is highly influenced by temperature, and sugar concentration increased significantly above $30^{\circ} \mathrm{C}$ (de Beer et al., 2005). Between 2005 and 2015, berries' sugar concentration was highly correlated with temperature and rainfall in both varieties (Sauvignon Blanc and Pinot Gris). 2005 was the coldest and one of the wettest years during research (2005-

TABLE 1

Sauvignon Blanc (SB) quality parameters in grape juice and wine, during 2005-2015.

\begin{tabular}{lllllc}
\hline Year & SB Sugars & SB Alch.\% & Juice SB TA $L^{-1}$ & Juice SB pH & Wine SB pH \\
\hline 2005 & 204 & 12.08 & 8.14 & 3.13 & 3.1 \\
2006 & 211 & 12.09 & 7.82 & 3.17 & 3.13 \\
2007 & 216 & 12.37 & 7.39 & 3.24 & 3.19 \\
2008 & 227 & 12.41 & 7.69 & 3.18 & 3.16 \\
2009 & 218 & 12.46 & 7.26 & 3.14 & 3.20 \\
2010 & 212 & 12.49 & 7.90 & 3.23 & 3.12 \\
2011 & 224 & 12.56 & 7.50 & 3.34 & 3.19 \\
2012 & 233 & 12.99 & 7.11 & 3.20 & 3.27 \\
2013 & 226 & 12.52 & 7.65 & 3.22 & 3.17 \\
2014 & 223 & 12.53 & 7.41 & 7.01 & 3.47 \\
\hline
\end{tabular}

SB - Sauvignon Blanc; Alch. - alcohol; TA - titratable acidity

TABLE 2

Pinot Gris (PG) parameters in grape juice and wine, during 2005-2015.

\begin{tabular}{|c|c|c|c|c|c|}
\hline Year & PG Sugars & PG Alch.\% & Juice PG TA $g L^{-1}$ & Juice $P G p H$ & Wine $P G p H$ \\
\hline 2005 & 219 & 12.32 & 7.99 & 3.31 & 3.19 \\
\hline 2006 & 231 & 12.56 & 7.69 & 3.42 & 3.21 \\
\hline 2007 & 242 & 12.67 & 7.45 & 3.46 & 3.27 \\
\hline 2008 & 240 & 12.66 & 7.54 & 3.42 & 3.24 \\
\hline 2009 & 249 & 12.70 & 7.20 & 3.48 & 3.29 \\
\hline 2010 & 239 & 12.67 & 7.79 & 3.39 & 3.20 \\
\hline 2011 & 251 & 12.69 & 7.46 & 3.46 & 3.26 \\
\hline 2012 & 254 & 13.07 & 7.17 & 3.50 & 3.32 \\
\hline 2013 & 247 & 12.71 & 7.49 & 3.43 & 3.24 \\
\hline 2014 & 246 & 12.70 & 7.47 & 3.44 & 3.25 \\
\hline 2015 & 260 & 13.18 & 7.01 & 3.52 & 3.36 \\
\hline
\end{tabular}

PG - Pinot gris; Alch. - alcohol; TA - titratable acidity 
2015), and sugar concentration was negatively influenced hereby. In 2012 and 2015, high temperatures above $18^{\circ} \mathrm{C}$ favoured sugar accumulation in Pinot Gris juice (Table 2). In both varieties, alcohol concentration was not majorly influenced by temperature and rainfall over the years. In wet years (2005, 2010, 2013 and 2014), Sauvignon Blanc which has tight clusters, was damaged by rot more than Pinot Gris. Viticultural practices and dryness decreases the sugars in 2014, close to the level of concentration in 2010.

\section{pH level}

Over-ripe due to the higher temperatures alters the wine flavours and acidity (Dobrei et al., 2015). The largest increase of $\mathrm{pH}$ in the Sauvignon Blanc variety was recorded in 2013, which was caused by reduced photosynthetic activity and high potassium concentration in berries. Although 2010 and 2015 were different in terms of climate, the juice and wine from the Sauvignon Blanc and Pinot Gris varieties had overall relatively close and moderate $\mathrm{pH}$ values, below 3.6 respectively (Table 1 and 2), which is favourable for stable wines.

\section{Titratable acidity}

The concentration of titratable acidity $\left(\mathrm{TA} \mathrm{L}^{-1}\right)$ of Sauvignon Blanc juice is over 7, which is the lowest desired for this variety, even though the acid profile is somewhat higher than in other wine varieties (Clarke, \& Bakker, 2004). In both varieties, TA of both juice and wine was the lowest in 2012, due to the warm weather and dilution with water in berries. The highest TA concentration was registered in 2014 because of the late harvesting, which correlated with water stress. For specific high acidity wines, the Sauvignon Blanc variety needs low temperatures (Jones et al., 2009). Results for TA in juice of white varieties, except in 2010, are in agreement with the observations of Myburgh (2006) in Sauvignon Blanc from South Africa (8.3-9.1 TA g L-1). The $\mathrm{pH}$ value of Sauvignon Blanc juice below 3.5 improved the colour stability and clarity of the wine. High temperatures and water stress in 2013 and 2014 resulted in grapes with low acidity/high $\mathrm{pH}$ for both Sauvignon Blanc and Pinot Gris. The higher TA in the Pinot Gris variety was found in juice from berries harvested in 2014, when temperature in ripening time (October) was low $\left(12^{\circ} \mathrm{C}\right)$.
Prediction for sugar content in Sauvignon Blanc and Pinot Gris varieties

\section{Sugar concentration influenced by temperature}

Since the accumulation of sugars influences the other components in berries and wine, regression analysis was done only for this parameter. Regression data analysis confirmed the prediction of Sauvignon Blanc and Pinot Gris sugar content based on the temperatures in the research area. Prediction of sugar content in Sauvignon Blanc and Pinot Gris varieties according to temperature (2005 - 2015) was statistically significant $\left(\mathrm{R}^{2}=0.545 ; \mathrm{p}<0.005\right)$, according to equation 1 , and $\left(\mathrm{R}^{2}=0.783 ; \mathrm{p}<0.001\right)$ equation 2 for Sauvignon Blanc. Equations $3\left(\mathrm{R}^{2}=0.519 ; \mathrm{p}<0.003\right)$ and 4 $\left(\mathrm{R}^{2}=0.888 ; \mathrm{p}<0.005\right)$ are available for Pinot Gris (Table 3$)$. The particular distribution of values is shown in Figure 5 $(a-d)$.

\section{Sugar concentration influenced by rainfall}

Correlated with temperature, precipitations are the second most important factor that influenced the grapevine growth, and consequently berry and wine quality (Chevet et al., 2011). Prediction of sugar content in both varieties according to monthly total rainfalls (2005 - 2015) was statistically significant $\left(\mathrm{R}^{2}=0.677 ; \mathrm{p}<0.001\right)$, according to equation 5 for both Sauvignon Blanc and for Pinot Gris $\left(\mathrm{R}^{2}=0.865\right.$; $\mathrm{p}<0.001$; equation 6) (Table 4). The particular distribution of values is shown in Figure $6(\mathrm{a}-\mathrm{d})$.

According to $\mathrm{R}^{2}$ results from Table 3 and 4, in both varieties temperature and rainfall from August influenced the sugar content in berries most. Water deficits in summer reduced shoot vigour and favoured the partitioning of carbohydrates through the clusters. Low levels of humidity and the favourable solar radiation in this period of veraison when colour of grapes is changing, lead to sugar level increase (Carey et al., 2009). Mirás-Avalos and Intrigliolo (2017) found in their research concerning the grape composition under water stress in a Mediterranean climate that this climate has a strong effect on the cultivar, since the weight of the Sauvignon Blanc and Riesling berries were strongly reduced. They found a correlation of -0.236 and 0.024 between grape sugars and vine water status.

The difference in vigour between varieties and berry development as a response to water limitation has a major

TABLE 3

Predictions for sugar content in grape juice of Sauvignon Blanc and Pinot Gris varieties, according to average monthly temperatures (2005 - 2015).

\begin{tabular}{|c|c|c|c|c|c|c|c|}
\hline & Parameter & Sauvignon Blanc & & $\mathrm{R}^{2}$ & Pinot Gris & & $\mathrm{R}^{2}$ \\
\hline May & \multirow{6}{*}{$\begin{array}{l}\text { Sugar/ } \\
\text { Temp. }\end{array}$} & $\mathrm{y}=-9.3413 x^{2}+318.13 x-2480.2$ & & 0.183 & $y=-8.0925 x^{2}+276.1 x-2106$ & & 0.163 \\
\hline June & & $\begin{array}{l}y=-2.4975 x^{2}+106.65 x-909.49 \\
p<0.005\end{array}$ & {$[1]$} & $0.545^{*}$ & $\begin{array}{l}y=-2.3504 x^{2}+100.35 x-821.13 \\
p<0.003\end{array}$ & [3] & $0.519 *$ \\
\hline July & & $\mathrm{y}=-0.083 x^{2}+8.5737 x+72.364$ & & 0.146 & $\mathrm{y}=5.2111 x+127.39$ & & 0.182 \\
\hline Aug & & $\begin{array}{l}y=0.1396 x^{2}+0.8938 x+132.052106 \\
p<0.001\end{array}$ & {$[2]$} & $0.783 *$ & $\begin{array}{l}y=0.1624 x^{2}+0.0538 x+160.74 \\
p<0.005\end{array}$ & {$[4]$} & $0.888 *$ \\
\hline Sept & & $\mathrm{y}=1.0834 x^{2}-36.738 x+528.95$ & & 0.199 & $y=1.1648 x^{2}-39.425 x+572.05$ & & 0.258 \\
\hline Oct & & $y=-0.27 x^{2}+9.5363 x+147.02$ & & 0.168 & $y=1.8 x+221.85$ & & 0.053 \\
\hline
\end{tabular}

*statistically significant 
impact on sugar accumulation, especially before veraison, according to Keller et al. (2006). The influence of water stress on grape quality was confirmed by Balint and Reynolds (2013) in Sauvignon Blanc from the Ontario region, where irrigation in the hot season improved grape composition and wine aroma.
Principal component analysis (PCA) was applied to Sauvignon Blanc and Pinot Gris varieties for grape juice and wine on the basis of sugars, alcohol content, titratable acidity and $\mathrm{pH}$ over the 11 years $(2005-2015)$. The PCA plot gives the overview of how analysed parameters were influenced by variety and by years. The first two main components (PC1

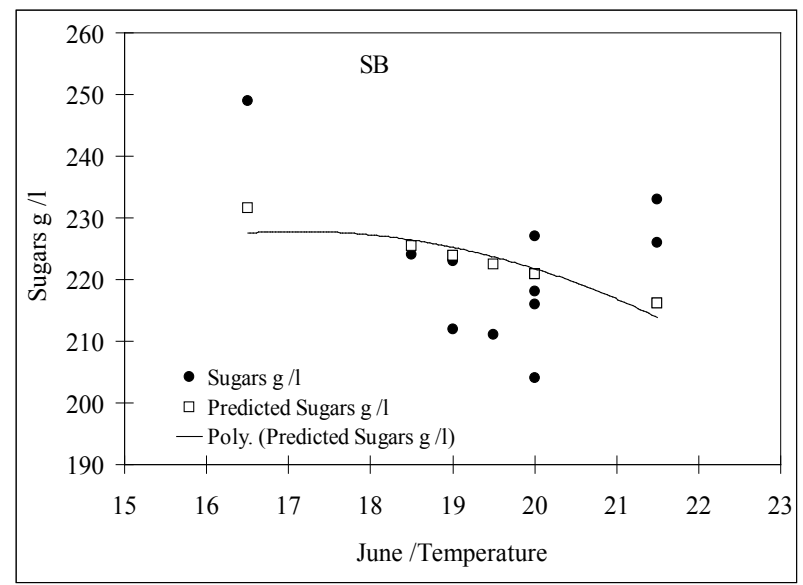

(a)

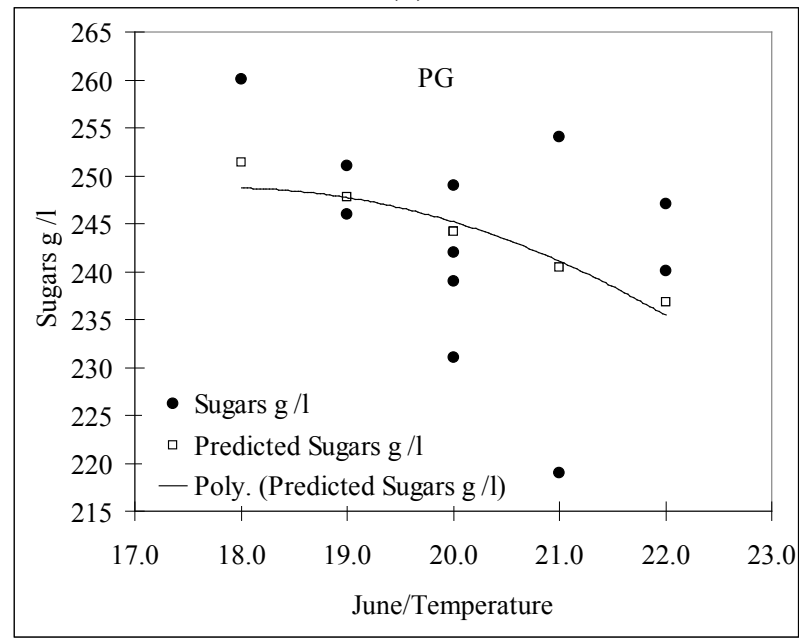

(c)

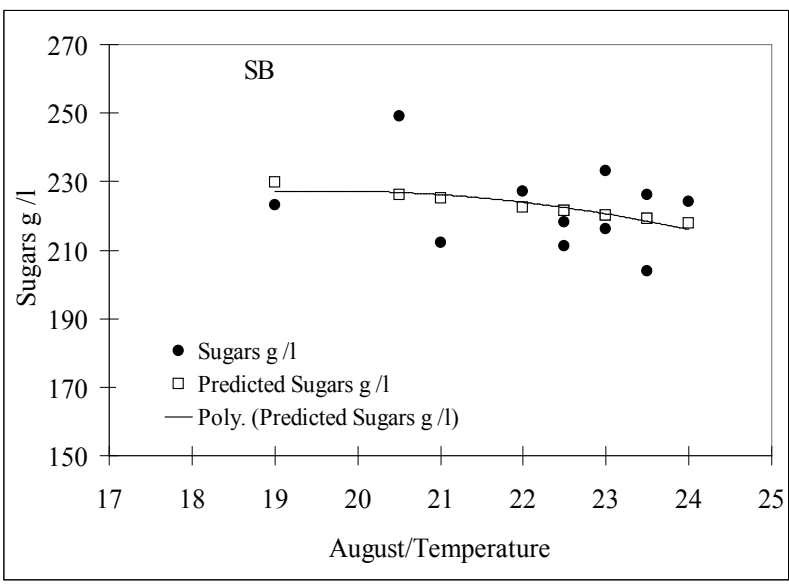

(b)

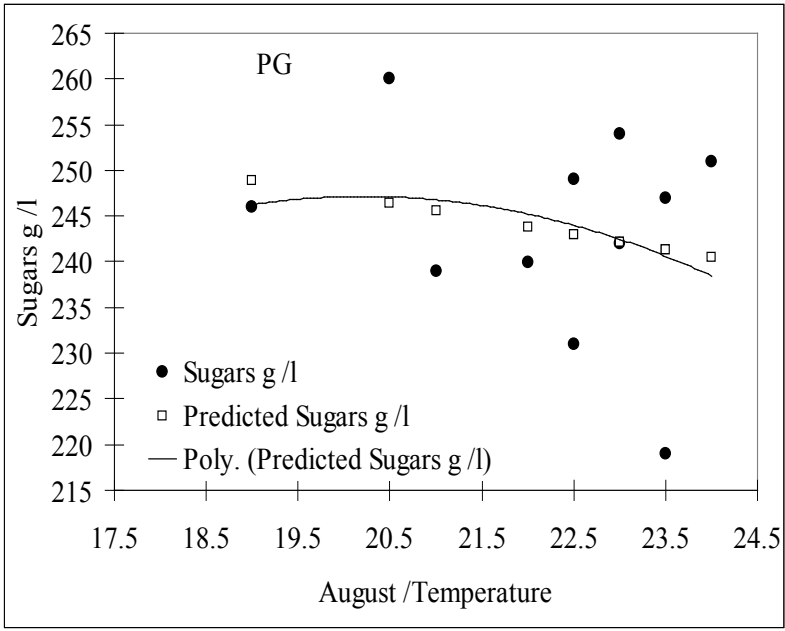

(d)

FIGURE 5

Predictions of sugar content in grape juice of Sauvignon Blanc (SB) and Pinot Gris (PG) grape varieties according monthly average temperatures in June and August (2005-2015)

TABLE 4

Predictions for sugar content in grape juice of Sauvignon Blanc and Pinot Gris varieties, according to total monthly rainfall (2005 - 2015).

\begin{tabular}{|c|c|c|c|c|c|c|c|}
\hline & Parameter & Sauvignon Blanc & & $\mathrm{R}^{2}$ & Pinot Gris & & $\mathrm{R}^{2}$ \\
\hline May & \multirow{6}{*}{$\begin{array}{l}\text { Sugar/ } \\
\text { Rainfall }\end{array}$} & $\mathrm{y}=-0.0063 x^{2}+0.9577 x+192.97$ & \multirow{6}{*}[5]{} & 0.244 & $y=-0.0094 x^{2}+1.4936 x+195.58$ & \multirow{6}{*}[6]{} & 0.565 \\
\hline June & & $\mathrm{y}=0.0022 x^{2}-0.5414 x+246.52$ & & 0.379 & $\mathrm{y}=0.0031 x^{2}-0.5954 x+266.22$ & & 0.236 \\
\hline July & & $\mathrm{y}=0.0029 x^{2}+0.5242 x+206.08$ & & 0.190 & $y=-0.0032 x^{2}+0.615 x+223.38$ & & 0.316 \\
\hline Aug & & $\begin{array}{l}y=0.0004 x^{2}-0.3105 x+239.59 \\
p<0.001\end{array}$ & & $0.677^{*}$ & $\begin{array}{l}y=-0.0922 x^{2}+10.534 x \\
p<0.001\end{array}$ & & $0.865^{*}$ \\
\hline Sept & & $y=-0.0003 x^{2}-0.1107 x+227.99$ & & 0.128 & $y=-0.0018 x^{2}-0.0205 x+249.4$ & & 0.288 \\
\hline Oct & & $y=-0.0044 x^{2}-0.1218 x+224.51$ & & 0.101 & $y=-0.0019 x^{2}-0.1073 x+250.17$ & & 0.145 \\
\hline
\end{tabular}

*statistically significant 


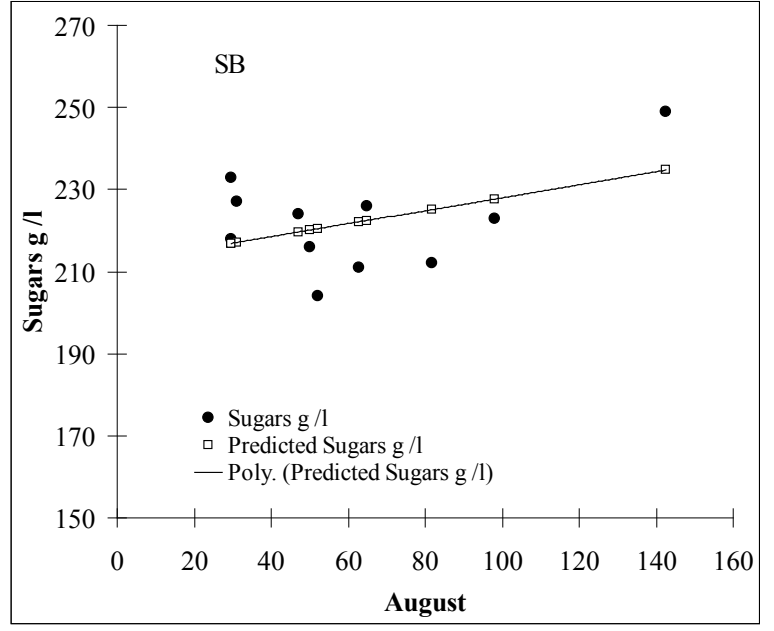

(a)

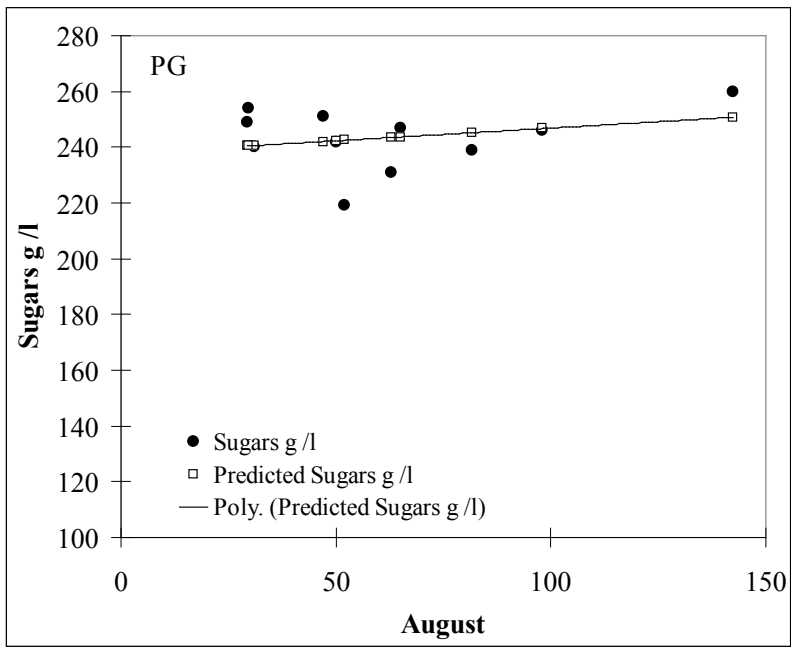

(c)

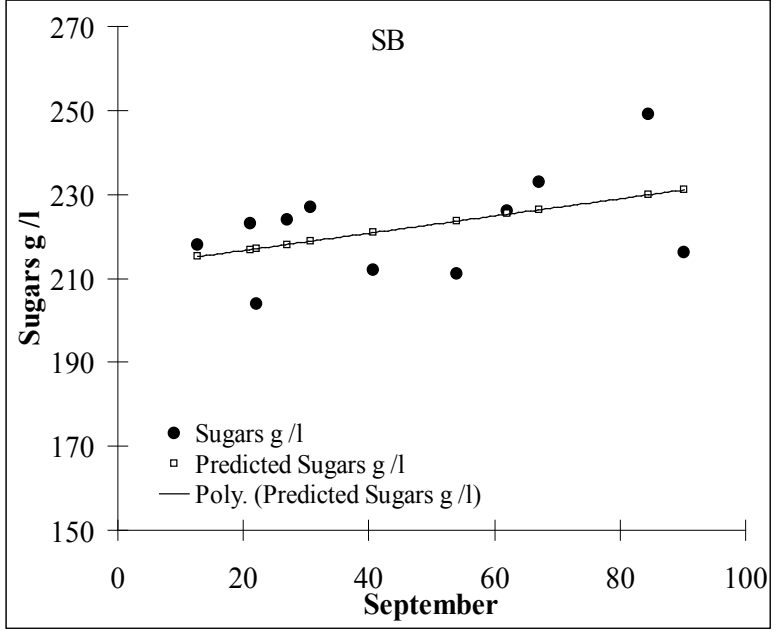

(b)

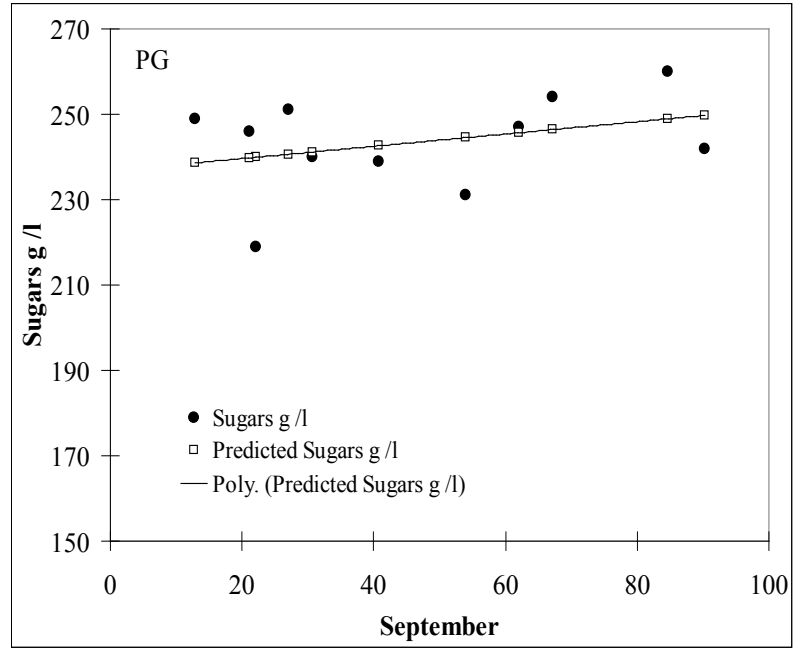

(d)

FIGURE 6

Predictions of sugar content in grape juice of Sauvignon Blanc (SB) and Pinot Gris (PG) grape varieties according monthly average rainfall in August and September (2005-2015).

and PC2) explains $94.44 \%$ of the experimental variance for those five traits studied for the Sauvignon Blanc variety, where PC1 explained $89.79 \%$ and PC2 explained $4.65 \%$ (Fig. 7). Factorial analysis revealed that alcohol content and sugar levels in the Sauvignon Blanc variety were higher over the years such as the balanced year of 2012 when the weather was warm and moderately wet, correlated with below average titratable acidity and grape juice or wine $\mathrm{pH}$ respectively.

In the Pinot Gris variety, multivariate analysis (Fig. 8) based on the first two main components explained $95.91 \%$ of the variability for the five parameters analysed. The sugars in the Pinot Gris grape juice was moderately influenced by the climatic conditions of the warmer and drier years (2012 and 2015), while the alcohol content was much higher than the average. In the moderate but warmer years (2010 and 2013), the titratable acidity was higher, while the $\mathrm{pH}$ of grape juice and wine was relatively low, especially in the warm and dry year of 2009 .

\section{DISCUSSION}

\section{Sugar accumulation and alcohol content}

High temperatures during ripening (average $20^{\circ} \mathrm{C}$ ) increased the sugar accumulation in both Sauvignon Blanc and Pinot Gris varieties, which is in accordance with the results of Coombe (1987). High levels of sugar concentration in juice are also due to dehydration of berries. In many research, results confirm that the optimum ripening temperature ranges between $20^{\circ} \mathrm{C}$ and $22^{\circ} \mathrm{C}$ (Gladstones, 2011). High sugar concentration and alcohol levels, correlated with low acidity, result in relatively unbalanced wine (Jackson, 2000). One of the issues generated by high alcohol content is that these wines will not age well and long, like those with moderate alcohol content do (Ashenfelter et al., 1995). Caliari et al. (2014), found in the Brazilian Santa Catarina region for the Sauvignon Blanc variety an alcohol content of $12.9 \pm 0.2 \%$, closely related to our values from 2015; while for Pinot Gris, value recorded was $10.5 \pm 0.2 \%$, much lower compared to the Pinot Gris alcohol content from the Timisoara region. 


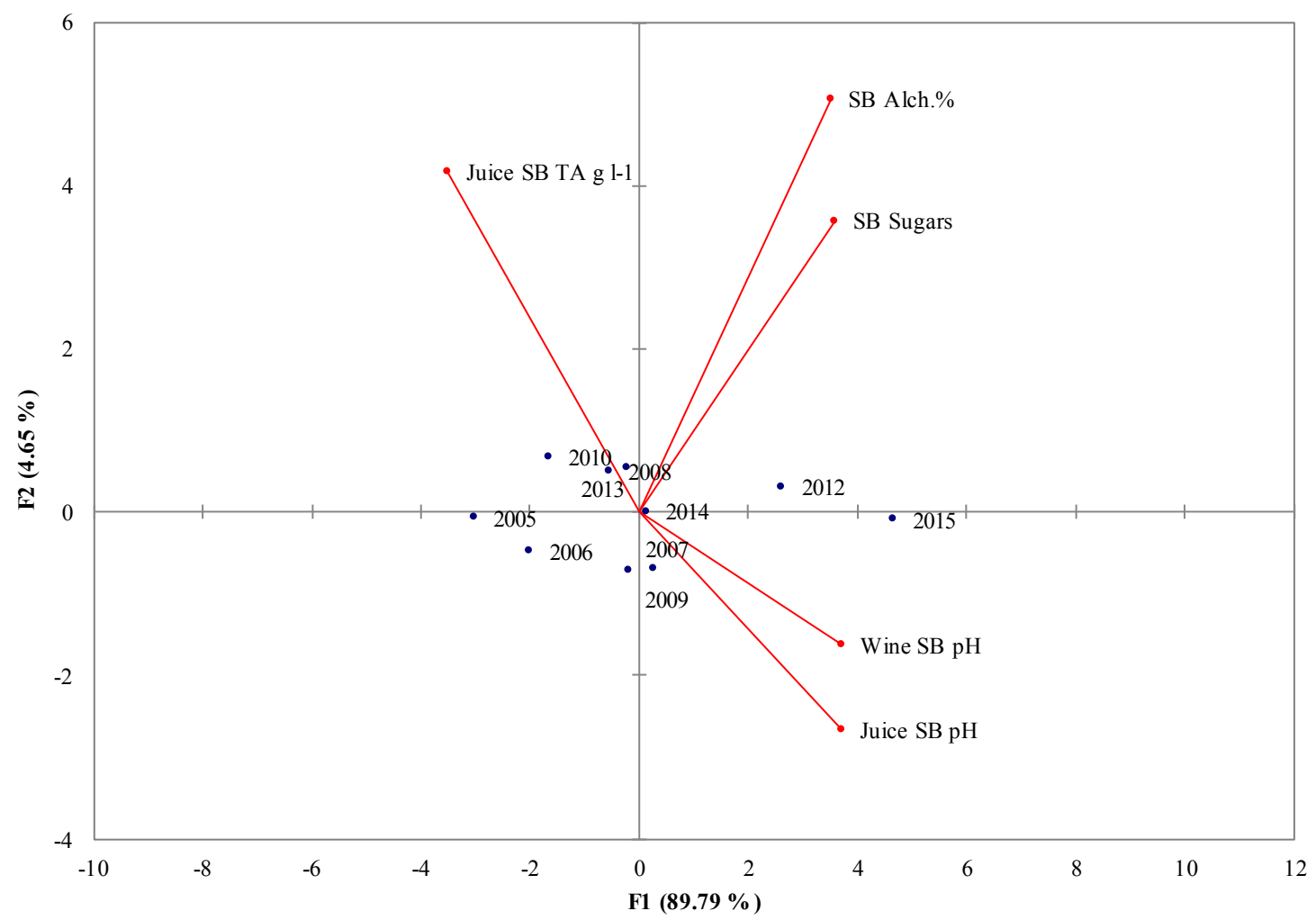

FIGURE 7

Principal component analysis of Sauvignon Blanc grape juice and wine and their characteristics (axes F1 and F2: 94.44 \%)

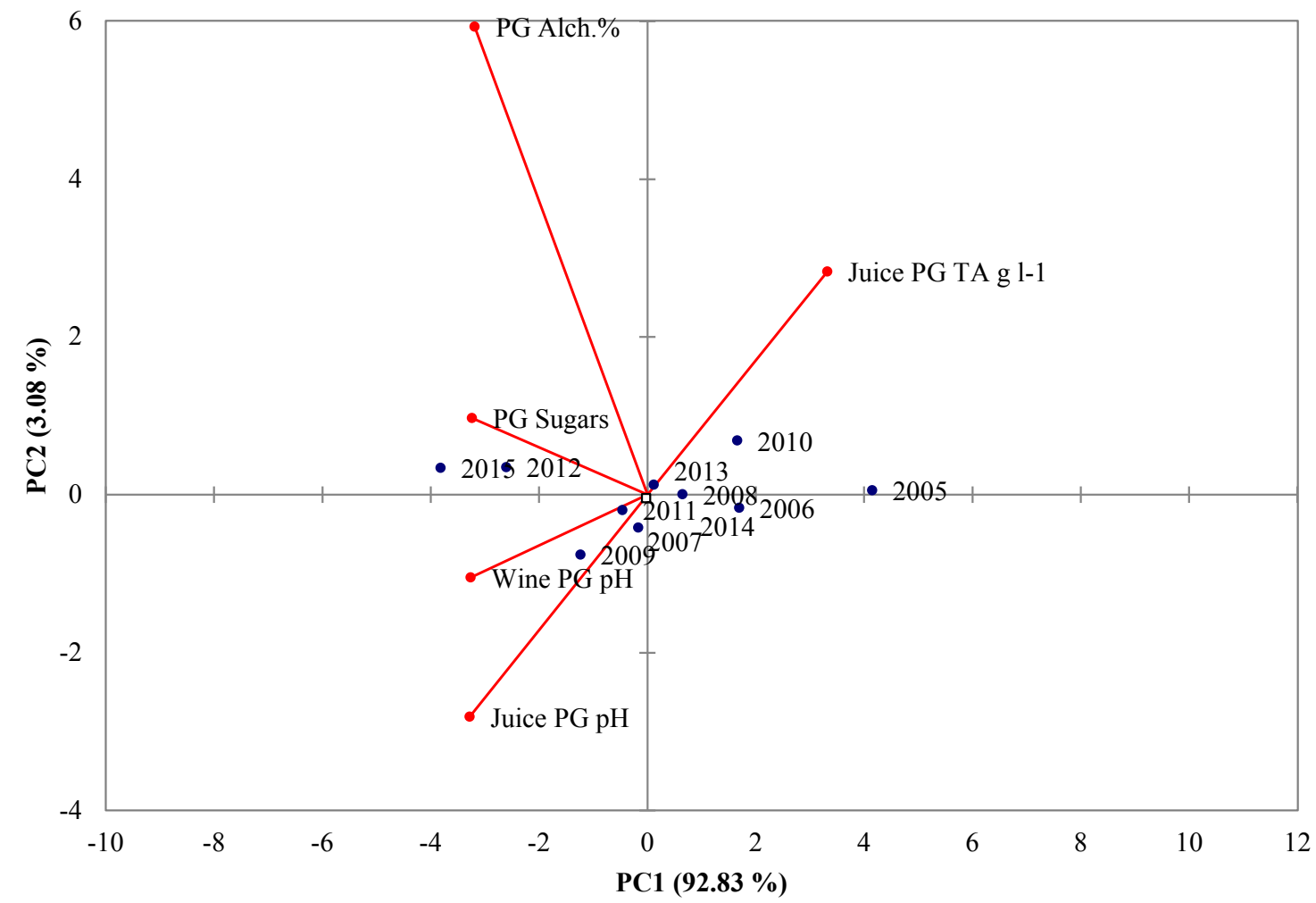

FIGURE 8

Principal component analysis of Pinot Gris grape juice and wine and their characteristics (axes PC1 and PC2: 95.91 \%) 


\section{pH level}

Conradie et al. (2002) found quite similar results for must $\mathrm{pH}$ in Sauvignon Blanc from South African vineyards (3.19 -3.30), with those from Sauvignon Blanc must from Romania (3.13 -3.47). Evaluating the leaf removal effect on berry composition in a Sauvignon Blanc vineyard from Italy, Mosetti et al. (2016) found (in control plot) a $\mathrm{pH}$ of 3.51 , associated with a TA of $4.88\left(\mathrm{~g} \mathrm{~L}^{-1}\right)$. Wine alcohol concentration ranged in the same limits or was lower than those obtained by Ford (2007) in his research on Sauvignon Blanc wine in New Zealand (12.7 -13.5\%). In the research of Tosi et al. (2008), Pinot Gris wine alcohol concentration ranged from 10.75 to $12.34 \%, \mathrm{pH}$ by 3.09 to 3.36 and phenols between 255 and $397 \mathrm{mg} \mathrm{L}^{-1}$. Shange and Conradie (2012) found the same influence of Botrytis cinerea on sugar accumulation for the Sauvignon Blanc variety grown in the Helderberg area of the Western Cape in South Africa. The $\mathrm{pH}$ value found in grape juice of Pinot Gris by Steiner et al. (2005) during 2001-2004 in Ohio State University vineyards, was between 3.12 and 3.24 (free run) in grape juice and between 2.96 and 3.22 in wine.

\section{Titratable acidity}

The influence of high temperature associated with water stress on TA/pH, was observed by Conradie et al. (2002) in several vineyards of Sauvignon Blanc from South Africa. Freeman et al. (1982) mentioned that for vineyards from Salinas Valley, among other factors, water stress reduces the photosynthetic activity in leaves, which leads to higher potassium accumulation in berries and increased must $\mathrm{pH}$ values. Bora et al. (2016) found a higher alcohol level of $14.35 \pm 0.25 \%$, and a lower TA $\left(5.20 \pm 0.07 \mathrm{~g} \mathrm{l}^{-1}\right)$ level in the eastern region of Romania (Dealu Bujorului from the Galati County located at $45^{\circ} 52^{\prime} 10^{\prime \prime}$ North, $27^{\circ} 55^{\prime} 8^{\prime \prime}$ East), in wine of the Sauvignon Blanc variety. In the same research, they found a higher $\mathrm{pH}$ level in the wine $(3.54 \pm 0.17)$. Grigorica et al. (2017) found in their research in the Sauvignon Blanc variety grown on sandy soils of the Oltenia region in the south of Romania during 2013-2015, the following values for wine parameters: alcohol level between 11.8\% (in 2014) and $13.6 \%$ (in 2015), TA between $5.9 \mathrm{~g} \mathrm{~L}^{-1}$ (in 2013) and $6.7 \mathrm{~g} \mathrm{~L}^{-1}$ (in 2015) and $\mathrm{pH}$ between 3.11 (in 2015) and 3.35 (in 2013). For the Pinot Gris variety grown in similar conditions, their results were: alcohol level from $12.9 \%$ (in 2014) to $13.8 \%$ (in 2015), TA from $5.8 \mathrm{~g} \mathrm{~L}^{-1}$ (in 2013) to $6.2 \mathrm{~g} \mathrm{~L}^{-1}$ (in 2015) and $\mathrm{pH}$ from 3.27 (in 2014) to 3.49 (in 2015). Their conclusion was that even in the years that are not very favourable for high quality white wines, good quality wines could be produced by adapted winemaking and biotechnological solutions. In their research from Stellenbosch in South Africa, Corey et al. (2009) found that must composition (sugars, $\mathrm{pH}$ and TA) of Sauvignon Blanc was not significantly influenced by climate variability. Wine aroma and acidity ( $\mathrm{pH} 3.6$ ) were determined by viticultural terroir.

Results obtained for TA in the Pinot Gris variety are closely related to those found by Tosi et al. (2008). By studying nine clones of Pinot Gris in the Verona region for three years (2002-2004), they found in the juice a TA between 6.75 and $10.45 \mathrm{~g} \mathrm{~L}^{-1}$ (harvested in the last decade of August), while $\mathrm{pH}$ ranged from 3.09 to 3.71 . Chemical analyses of juice done by Olejar et al. (2015) in New Zealand revealed higher TA (10.1 $\left.\mathrm{g} \mathrm{L}^{-1}\right)$ and $\mathrm{pH}$ (3.4) because of cryogenic maceration. In the dry summers and higher temperatures of 2012 and 2015, grapes matured earlier and therefore have a lower TA value in both varieties. In traditional Cencibel vineyards from Spain, Ortiz-Villajos et al. (2010) found that TA is decreasing from the end of July until the ripening time in September, from $13.5 \mathrm{~g} \mathrm{~L}^{-1}$ to $4.4 \mathrm{~g} \mathrm{~L}^{-1}$ in 2008 (a mild, fresh year in Spain), and from $9.5 \mathrm{~g} \mathrm{~L}^{-1}$ to $4 \mathrm{~g} \mathrm{~L}^{-1}$ in 2009 (a warm and dry year in Spain), respectively.

\section{CONCLUSIONS}

High sugar concentration in juice leads to undesirable fermentation products, suchas acetic acid. Among the white varieties, Sauvignon Blanc alcohol concentration fluctuated little over the years, and was found to be moderately low or medium alcohol concentrated wines. The temperature and rainfall study during April - October on grapevine vegetation is useful for prediction and adjustments in pruning and management technologies of main quality parameters in juice and wine. Rainfall and temperatures had very large amplitudes in the years and months of research, but in the research area, June and July influenced the vegetative cycle of the grapevine most, delaying or accelerating the development of the foliar area or the ripening and harvesting time, which has a direct influence on wine products. Knowing the behavior of the vineyard in reaction to climate change is helpful in order to be able to coordinate the grapevine management and pruning throughout the year, and to finally get the best juice and wine. At higher temperatures the grapevine phenology cycles start earlier, which means that sugars and tannins are fully developed before harvest. Hot weather induces faster sugar maturation without flavour fulfillment. If the harvest waits for flavour development, the acidity is sacrificed, resulting in high alcohol wine with low acidity. In ideal climates, sugar accumulation happens steadily, acidity level is regulated and the final result is the flavour palate of the wine. Understanding the relationship between grapevine phenology and temperature helps viticulturists with future vineyard management planning and to find suitable solutions. Results of the research offer new information for winemakers concerning the quality traits of juice and wine of Sauvignon Blanc and Pinot Gris varieties, which could be useful for their marketing and promotion.

\section{LITERATURE CITED}

Ashenfelter, O., Ashmore, D. \& Lalonde, R., 1995. Bordeaux wine vintage quality and the weather. Chance. 8, 7-13.

Ashenfelter, O. \& Storchmann, K., 2014. Wine and climate change. AAWE Working Paper No. 152 - Economics. American Association of Wine Economists. 8th Annual Conference, June 2014, Walla Walla, Washington. pp. 1-42.

Balint, G. \& Reynolds, A.G., 2013. Effect of different irrigation strategies on vine physiology, yield, grape composition and sensory profile of Sauvignon Blanc (Vitis vinifera L.) in a cool climate area. Journal International des Sciences de la Vigne et du Vin. 47, 159 -181.

Bora, F.D., Donici, A., Oşlobanu, A., Fitiu, A., Babes, A.C. \& Bunea, C.I., 2016. Qualitative assessment of the white wine varieties grown in Dealu Bujorului vineyard, Romania. Not. Bot. Horti. Agrobo. 4, 593-602. 
Caliari, V., Burin, V.M., Rosier, J.P. \& BordignonLuiz, M.T., 2014. Aromatic profile of Brazilian sparkling wines produced with classical and innovative grape varieties. Food Res. Int. 62, 965-973.

Carey, V.A., Archer, E., Barbeau G., Barbeau G. \& Saayman D., 2009, Viticultural terroirs in Stellenbosch, South Africa. III. Spatialisation of viticultural and oenological potential for Cabernet-Sauvignon and Sauvignon Blanc by means of a preliminary model. J. Int. Sci. Vigne Vin. 43, 1-12.

Chevet, J.M., Lecocq, S. \& Visser, M., 2011. Climate, grapevine phenology, wine production, and prices: Pauillac (1800-2009). American Economic Review. 101, 142-146.

Christidis, N., Jones, G.S. \& Stott, P.A., 2015. Dramatically increasing chance of extremely hot summers since the 2003 European heatwave. Nat. Clim. Change. 5, 46-50.

Clarke, O. \& Rand, M., 2001. Oz Clarke's Encyclopedia of Grapes. Harcourt, Cornell University.

Clarke, R.J. \& Bakker, J., 2004. Wine: Flavour Chemistry. Blackwell Publishing Ltd, Oxford.

Coetzee, C. \& du Toit W.J., 2015. Sauvignon Blanc wine: contribution of ageing and oxygen on aromatic and non-aromatic compounds and sensory composition - a review. S. Afr. J. Enol. Vitic. 36, 347 -365.

Conradie, W.J., Carey, V.A., Bonnardot, V., Saayman, D. \& van Schoor, L.H., 2002. Effect of different environmental factors on the performance of Sauvignon Blanc grapevines in the Stellenbosch/Durbanville districts of South Africa. I. Geology, Soil, Climate, Phenology and Grape Composition. S. Afr. J. Enol. Vitic. 23, 78-91.

Coombe, B., 1987. Influence of temperature on composition and quality of grapes. ISHS Acta Horticulturae. 206, 25-35.

De Beer, D., Joubert, E., Gelderblom, W.C.A. \& Manley, M., 2005. Changes in the phenolic composition and antioxidant activity of Pinotage, Cabernet Sauvignon, Chardonnay and Chenin Blanc wines during bottle ageing. S. Afr. J. Enol. Vitic. 26, 6-15.

Dobrei, A.G., Dobrei, A., Nistor, E., Sala, F., Mălăescu, M., Drăgunescu, A. \& Camen, D., 2015. Research concerning the qualitative potential of the wines obtained from different grape-growing ecosystems. J. Hort. Forest. Biotech. 19, 103- 107.

Daux, V., Garcia de Cortazar-Atauri, I., Yiou, P., Chuine, I., Garnier, E. \& Le Roy Ladurie, E., 2011. An open-access database of grape harvest dates for climate research: data description and quality assessment. Clim. Past. $8,1403-1418$.

Freeman, B.M., Kliewer, W.M. \& Stern, P., 1982. Influence of wind breaks and climatic region on diurnal fluctuation of leaf water potential, stomatal conductance, and leaf temperature of grapevines. Am. J. Enol. Vitic. 33, 233-236.

Ford, R.J., 2007. The effect of shading and crop load on flavour and aroma compounds in Sauvignon Blanc grapes and wine. Thesis, Lincoln University, Lincoln, New Zealand.

Gerós, H., Chaves, M. \& Delrot, S., 2012. The biochemistry of the grape berry. Bentham Science Publishers. eISBN: 978-160805-360-5. p. 102.

Gladstones, J., 2011. Wine, terroir and climate change. Wakefield Press, Australia.

Grigorica, L.G, Niculaua, M., Nechita, C.B., Nistor A.M. \& Cotea V.V., 2017. The impact of some commercial yeast strains on aroma compounds and sensorial analysis on two white wine varieties made in PGI Dealurile Olteniei, Romania. 40th World Congress of Vine and Wine, BIO Web of Conferences 9, 02006. doi: 10.1051/bioconf/20170902006.
Irimia, L.M., Patriche, C.V., Roșca, B. \& Cotea V., 2017. Modifications in climate suitability for wine production of Romanian wine regions as a result of climate change. 40th World Vine and Wine Congress, June 2017, Sofia, Bulgaria. pp. 32-33.

Jackson, R.S., 2000 (2nd ed). Wine science: principles, practice, perception. Academic Press, San Diego.

Jones, G. \& Davis, R., 2000. Climate influences on grapevine phenology. Grape composition and wine production and quality for Bordeaux, France. Am. J. Enol. Vitic. 51, 249-261.

Jones, G., Moriondo, M., Bois, B., Hall, A., \& Duff, A., 2009. Analysis of the spatial climate structure in viticulture regions worldwide. Bull l'OIV. 12,507 .

Jones, G.V., Reid, R. \& Vilks, A., 2012. Climate, grapes, and wine: structure and suitability in a variable and changing climate. In: Dougherty, P.H. (ed). The Geography of Wine: Regions, Terroir and Techniques. Springer, New York and Berlin.

Jones, G.V. \& Alves, F., 2012. Impact of climate change on wine production: a global overview and regional assessment in the Douro Valley of Portugal. Int. J. Global Warming. 4, 383-406.

Keller, M., Smith, J.P. \& Bondada, B.R., 2006. Ripening grape berries remain hydraulically connected to the shoot. Journal of Exp. Botany. 57, $2577-2587$.

Lorenzo, M.N., Taboada, J.J., Lorenzo, J.F. \& Ramos, A.M., 2012. Influence of climate on grape production and wine quality in the Rras Baixas, northwestern Spain. Regional Environmental Change. 12, 1-12.

Malheiro, A.C., Campos, R., Fraga, H., Eiras-Dias, J., Silvestre, J. \& Santos, J.A., 2013. Winegrape phenology and temperature relationships in the Lisbon wine region, Portugal. J. Int. des Sci. de la Vigne et du Vin. 47, 287-299.

Mirás-Avalos, J.M. \& Intrigliolo, D.S., 2017. Grape composition under abiotic constraints: water stress and salinity. Front. Plant Sci. 8, 1-8.

McQuaid, J., 2011. What rising temperatures may mean for world's wine industry. Yale Environment 360. Report. available at: http://e360.yale.edu/ feature/what global warming may mean for worlds wine industry/2478.

Mosetti, D., Herrera, J.C., Sabbatini, P., Green, A., Alberti, G., Peterlunger, E., Lisjak, K. \& Castellarin, S.D., 2016. Impact of leaf removal after berry set on fruit composition and bunch rot in Sauvignon Blanc. Vitis. 55, 57-64.

Myburgh, P.A., 2006. Juice and wine quality responses of Vitis vinifera L. cvs. Sauvignon Blanc and Chenin Blanc to timing of irrigation during berry ripening in the coastal region of South Africa. S. Afr. J. Enol. Vitic. 27, 1-7.

Nesbitt, A., Kemp, B., Steele, C., Lovett, A. \& Dorling, S., 2016. Impact of recent climate change and weather variability on the viability of UK viticulture - combining weather and climate records with producers' perspectives. Austr. J. Grape Wine Res. 22, 324-335.

Olejar, K.J., Fedrizzi, B. \& Kilmartin, P.A., 2015. Influence of harvesting technique and maceration process on aroma and phenolic attributes of Sauvignon Blanc wine. Food Chem. 183, 181-189.

Ortiz-Villajos, J.A.A., de Cuerva, F.M., de los Reyes, C.P., Navarro, F.J., Gallego, G. \& Campos, J.A., 2010. Climate effect on ripening process in Vitis vinifera, L. Cv. Cencibel, VIII International Terroir Congress, June 2010, Soave, Italy. pp. $42-46$.

Robinson, J. \& Harding, J., 2015. (4 ${ }^{\text {th }}$ ed). The Oxford companion to wine. Oxford University Press, Oxford.

Robinson, J., 1986, Vines Grapes \& Wines. Mitchell Beazley. ISBN 1-85732999-6. 
Shange, L.P. \& Conradie, W.J., 2012. Effects of soil parent material and climate on the performance of Vitis vinifera L. cvs. Sauvignon Blanc and Cabernet Sauvignon - Part II. Climate, Leaf Analysis, Juice Analysis and Wine Quality. S. Afr. J. Enol. Vitic. 33, 161-173.

Singleton, V.L. \& Rossi, J.A., 1965. Colorimetry of total phenolics with phosphomolybdic-phosphotungstic acid reagents. Am. J. Enol. Vitic. 16, 144-158.

Steiner, T., Gallander, J. \& Firth, E., 2005. Influence of various pressing treatments on the quality of Pinot Gris wines. The Ohio State University/ OARDC, Wooster, OH 44691. https://kb.osu.edu/dspace/bitstream/.../ OARDC_HCS_0744_paper_07_Steiner.pdf?
Tosi, E., Tezza, G. \& Bletzo, C., 2008. Il Pinot grigio. Volume Terre d'Arcole. pp. 205-227.

Weston, L.A., 2000. Grape and wine tannins and phenolics - their roles in flavour. Quality and human health. Department of Horticulture. Cornell University. Ithaca NY 14853. 29th Annual New York Wine Industry Workshop. pp. 6-14.http://street-map.us/gps/ 